\title{
Article \\ Comparative Performance Evaluation of Commercial Packing Materials for Malodorants Abatement in Biofiltration
}

\author{
Raquel Lebrero $^{1}{ }^{(\mathbb{D}}$, Elisa Rodríguez ${ }^{1}$, María Collantes ${ }^{1}{ }^{(\mathbb{D}}$, Carlos De Juan ${ }^{2}$, Geir Norden ${ }^{2}$, Kim Rosenbom ${ }^{2}$ \\ and Raúl Muñoz 1,*iD
}

Citation: Lebrero, R.; Rodríguez, E.; Collantes, M.; De Juan, C.;

Norden, G.; Rosenbom, K.; Muñoz, R. Comparative Performance Evaluation of Commercial Packing Materials for Malodorants Abatement in Biofiltration. Appl. Sci. 2021, 11, 2966. https://doi.org/10.3390/ app11072966

Academic Editors: Selena Sironi, Laura Maria Teresa Capelli and Marzio Invernizzi

Received: 28 February 2021

Accepted: 22 March 2021

Published: 26 March 2021

Publisher's Note: MDPI stays neutral with regard to jurisdictional claims in published maps and institutional affiliations.

Copyright: (c) 2021 by the authors. Licensee MDPI, Basel, Switzerland. This article is an open access article distributed under the terms and conditions of the Creative Commons Attribution (CC BY) license (https:/ / creativecommons.org/licenses/by/ $4.0 /)$.
1 Institute of Sustainable Processes, University of Valladolid, Mergelina s/n., 47011 Valladolid, Spain; raquel.lebrero@iq.uva.es (R.L.); elisamaria.rodriguez@uva.es (E.R.); maria.collantes@alumnos.uva.es (M.C.)

2 SAINT GOBAIN, LECA INTERNATIONAL, Robert Jacobsens Vej 62A, 2300 Københavny, Denmark; Carlos.deJuan@saint-gobain.com (C.D.J.); Geir.Norden@leca.no (G.N.); kim.rosenbom@saint-gobain.com (K.R.)

* Correspondence: mutora@iq.uva.es; Tel.: +34-983-1864224

Featured Application: Packing materials used in biofiltration play a key role to ensure a costeffective air pollutant abatement. Indeed, the selection of a suitable material might reduce operating costs, improve system performance and facilitate biofilters or biotrickling filter maintenance. This study demonstrated the suitability of a novel clay-based material to efficiently remove malodorants at low pressure drops.

Abstract: Packing materials used in biofiltration of gaseous pollutants represent a key design parameter, as a proper selection might not only determine the adequate performance of the system but also its cost-effectiveness. This study systematically assessed and compared the performance of a conventional plastic carrier with that of two novel clay-based materials from SAINT GOBAIN for the abatement of a model odorous stream composed of $\mathrm{H}_{2} \mathrm{~S}$, methylmercaptan and toluene. The packing materials were tested in biotrickling filters, biofilters and a two-phase biotrickling filter. SAINT GOBAIN materials exhibited a higher adsorption potential under abiotic conditions, a higher buffer capacity and a superior performance compared to conventional plastic rings when implemented in biotrickling filters operating at gas residence times as low as $7.5 \mathrm{~s}$. Among the materials tested in biofilters, Filtralite Air AC supported almost complete $\mathrm{H}_{2} \mathrm{~S}$ and toluene removals at a gas residence time of $20 \mathrm{~s}$, while successfully eliminating methylmercaptan at values of $\sim 80 \%$. Interestingly, under most of the conditions tested, clay-based materials also showed comparable pressure drop values than those of plastic rings.

Keywords: biofiltration; Filtralite; odour treatment; packing material; pressure drop; two-phase biotrickling filter

\section{Introduction}

Odour abatement from industrial activities, in particular from wastewater or waste management activities, still represents a significant concern to plant operators due to the gradual encroachment of cities on industrial park and the ever stricter environmental regulations [1]. Despite odorant prevention strategies are applied at source, the implementation of active end-of-the-pipe technologies is often needed to mitigate odour nuisance. In this context, physical-chemical technologies such as incineration, activated carbon adsorption or chemical scrubbing exhibit high operating costs and environmental impacts, which has recently paved the way to odour-treatment biotechnologies [2]. Biotechnologies are based on the biocatalytic action of fungi and bacteria to oxidize, at ambient pressure and temperature, the malodorous compounds present in industrial emissions at significantly lower operating costs and environmental impacts than their physical-chemical counterparts. Bioscrubbers, biofilters and biotrickling filters rank among the most popular biotechnologies 
for odour abatement, although biotrickling filters (BTFs) are increasingly implemented due to their lower footprint, reduced operating cost and high efficiency [3]. However, the high removal performance recorded in BTFs is commonly limited to the highly soluble VOC fraction of the polluted emission, while the abatement of the hydrophobic odorants is commonly restricted due to their low mass transfer rates from the gas to the microbialcontaining aqueous phase as a result of their low aqueous solubility [4]. In this context, the addition of a non-aqueous phase to conventional biotrickling filters (i.e., two-phase partitioning bioreactors or TPPB) may boost the removal of the hydrophobic fraction of the odorous emission by enhancing the transport of these compounds from the gas to the microbial degrading community [4].

Despite the significant advances in biological odour removal technologies in the past 20 years, packing material selection still represents the most uncertain and critical design variable in biofiltration systems. This is paradoxical since packing material ultimately determines odorant removal efficiency and process operating costs (i.e., pressure drop across the bed and frequency of packing replacement) [5]. In this context, packing materials should meet certain design specifications in order to ensure the most suitable environment for microbial growth and foster gas-liquid mass transfer: high specific surface area and porosity, near-uniform particle size to enhance gas-biofilm exchange and gas distribution throughout the bed, good water retention capacity to avoid biofilter desiccation, significant pH-buffering capacity, high nutrients content, diverse microflora, etc. Additionally, low cost, market availability and good structural properties (to avoid compaction of the bed) are of utmost importance [5,6].

A compilation of data from full-scale installations revealed that approximately $87 \%$ of the biofilters were operated with organic packing materials, wood chips and compost from primary sources such as bark, wood residue, yard trash or agricultural waste being the most popular supports [7,8]. Compost offers a high specific surface area and porosity, high nutrients content, high microbial diversity, good water holding capacity, easy availability and low cost [6]. Thus, compost-based biofilters have been implemented for the abatement of numerous volatile organic and inorganic compounds (VOCs and VICs) present in gaseous emissions within a wide range of concentrations (from trace levels up to several $\mathrm{g} \mathrm{m}^{-3}$ ) [6,9]. However, compost also lacks from structural stability and compacts easily, resulting in high pressure drops across the packed bed and therefore high energy consumptions. The pressure drop also limits the height of the compost-based biofilter to about 1.5 $\mathrm{m}$, resulting in significant area requirements. In addition, as reported by Janni et al. [10], organic filter beds, such as peat, soil or compost, are commonly characterized by a low adsorption capacity. Thus, compost is commonly used associated with a bulking agent (such as vermiculite, perlite, or woodchips) necessary to extend its lifetime and improve the structural stability of biofilters; or even mixed with another material with higher adsorption potential $[6,11]$. During operation, compost media also deteriorates due to the activity of microbial populations, constant wetting and drying, volatilization and leaching of nutrients, among other factors [12]. Several authors have associated this premature deterioration of compost media with a decrease in biofilter performance, since it results in acidification, compaction, excessive dryness, loss of structure, short circuiting, channel formation, and/or clogging. Thus, compost media offers a reduced lifetime compared with other materials, and must be replaced every two to five years [12,13].

On the contrary, the lifespan of inert carriers such as polyurethane foam, activated carbon, plastic rings or lava rock outperforms that of organic materials, representing the preferred packing in biotrickling filters [14]. Thus, their higher manufacture costs are outweighed by their longer lifetime and high performance. The properties of inorganic packing materials significantly vary from one to another: density, void fraction, roughness of the surface, etc. In general, inert packing materials are characterized by a higher physical strength, a much more regular shape and suffer less (physical, chemical and/or biological) deterioration over time, significantly reducing channeling problems, bed compaction and pressure drop. However, biomass growth on conventional inert carriers is usually hindered 
by the absence of nutrients, whose addition is required to ensure efficient biodegradation performance, the challenging adhesion of microorganisms (increasing the start-up period) and their low water retention capacity $[15,16]$.

Therefore, the development of new tailored-made packing materials that exhibit the merits of both organic and inorganic carriers (i.e., by providing a good specific surface area, water retention capacity and structural stability) while being competitive in the market, is of paramount importance to ensure a cost-effective operation of biofilters and biotrickling filters for odour control. In this context, the company SAINT GOBAIN has developed two novel clay-based packing materials, namely Filtralite ${ }^{\circledR}$ AIR $10-20$ mm and Filtralite ${ }^{\circledR}$ Air AC, that meet the necessary requirements for odorants biofiltration. Both materials have been conceived at an industrial level in such a way that they can be produced in the different expanded clay plants that Saint Gobain has in Europe. This study comparatively assessed the performance of conventional plastic rings and both materials from the company SAINT GOBAIN for the abatement of an odorous emission in biofilters (BFs) and biotrickling filters (BTFs) operated at multiple gas residence times. The influence of the packing material and operation mode on the structure of the microbial community was also assessed.

\section{Materials and Methods}

\subsection{Inoculum and Mineral Salt Medium}

The BTFs and BFs were inoculated with $0.2 \mathrm{~L}$ of fresh activated sludge from Valladolid wastewater treatment plant (Spain). The mineral salt medium (MSM) used in the bioreactors was composed of (g/L): $\mathrm{K}_{2} \mathrm{HPO}_{4}(0.7) ; \mathrm{KH}_{2} \mathrm{PO}_{4} \cdot 3 \mathrm{H}_{2} \mathrm{O}(0.917) ; \mathrm{KNO}_{3}$ (3); $\mathrm{NaCl}(0.2) ; \mathrm{MgSO}_{4} \cdot 7 \mathrm{H}_{2} \mathrm{O}(0.345)$ and $\mathrm{CaCl}_{2} \cdot 2 \mathrm{H}_{2} \mathrm{O}(0.026)$. Trace elements were supplied by adding $2 \mathrm{~mL} \mathrm{~L}^{-1}$ of SL-4 stock solution containing ( $\left.\mathrm{g} \mathrm{L}^{-1}\right)$ : EDTA (0.5); $\mathrm{FeSO}_{4} \cdot 7 \mathrm{H}_{2} \mathrm{O}$ (0.2); $\mathrm{ZnSO}_{4} \cdot 7 \mathrm{H}_{2} \mathrm{O}(0.01) ; \mathrm{MnCl}_{2} \cdot 4 \mathrm{H}_{2} \mathrm{O}(0.003) ; \mathrm{H}_{3} \mathrm{BO}_{3}$ (0.345); $\mathrm{CoCl}_{2} \cdot 6 \mathrm{H}_{2} \mathrm{O}(0.02) ; \mathrm{CuCl}_{2}$. $2 \mathrm{H}_{2} \mathrm{O}(0.001) ; \mathrm{NiCl}_{2} \cdot 6 \mathrm{H}_{2} \mathrm{O}(0.002) ; \mathrm{Na}_{2} \mathrm{MoO}_{4} \cdot 6 \mathrm{H}_{2} \mathrm{O}(0.003)$.

\subsection{Experimental Setup and Operational Procedure}

The experiment was divided into two operational phases as described below.

Phase I. The experimental set-up for malodorous air treatment consisted of three identical PVC biotrickling filters (internal diameter $=0.1 \mathrm{~m}$, height $=1 \mathrm{~m}$, total working volume $=2.5 \mathrm{~L}$ ) packed with three different materials: Filtralite AIR 10-20 mm (BTF-F), Filtralite AIR AC (BTF-FAC) and Kaldnes K2 plastic rings (BTF-K) (Figure 1) (Table 1). The air stream entering the system was first pumped through an activated carbon filter, where any residual pollutant from the atmospheric air was eliminated. The air was then humidified in a water column, entering afterwards a mixing chamber. In the mixing chamber, the clean and humidified air stream was mixed with a synthetic mixture of $\mathrm{H}_{2} \mathrm{~S}$, toluene and methyl mercaptan in $\mathrm{N}_{2}$ (purchased to Abelló Linde, Barcelona, Spain). The resulting polluted stream was divided into three identical streams of $1.25 \mathrm{~L} \mathrm{~min}^{-1}$ by means of rotameters. The individual streams were then fed at the bottom of each biotrickling filter. The clean air exiting the biotrickling filters was discharged outside the room using an extraction fan. Three 0.5-L holding tanks magnetically stirred were used as liquid mineral salt medium (MSM) reservoirs, containing the required nutrients for the microbial community. The liquid was continuously recycled through the packed beds at a flowrate of $0.15 \mathrm{~L} \mathrm{~min}^{-1}$ countercurrently with the polluted air stream (liquid trickling velocity of $\left.2 \mathrm{~m} \mathrm{~h}^{-1}\right)$. 


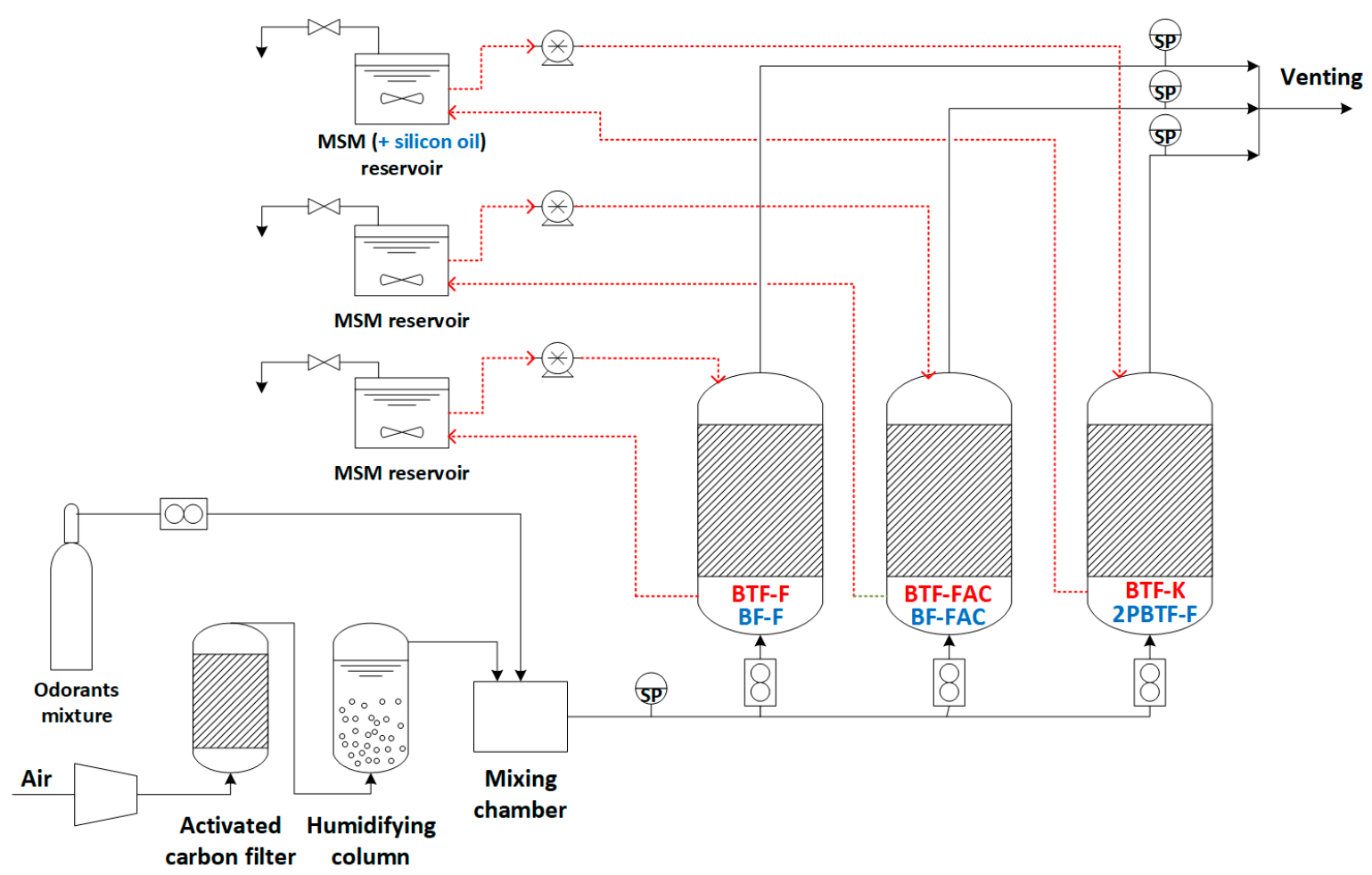

Figure 1. Schematic representation of the experimental setup (red: Phase I, blue: Phase II). Irrigation to the bioreactors (dotted lines) was either intermittent (BFs) or continuous (BTFs). SP: sampling port; MSM: mineral salt medium.

Table 1. Main characterization parameters of the packing materials tested.

\begin{tabular}{cccccc}
\hline & Acronym & $\begin{array}{c}\text { Density } \\
\left(\mathbf{k g ~ m}^{-3} \mathbf{)}\right.\end{array}$ & Porosity & Particle Size & Material \\
\hline Kaldnes K2 & $\mathrm{K}$ & $\begin{array}{c}950 \\
\text { Bulk: } 700\end{array}$ & $85 \%$ & $10 \mathrm{~mm}$ & $\begin{array}{c}\text { Polyethylene (PEHD) } \\
\text { Solid grains of thermally } \\
\text { treated clay }\end{array}$ \\
Filtralite AIR AC & FAC & $\begin{array}{c}\text { Particle: } 1900 \\
\text { Bulk: } 275 \\
\text { Particle: } 584\end{array}$ & $63 \%$ & $0.5-2 \mathrm{~mm}$ & Expanded clay \\
\hline
\end{tabular}

A 9-days abiotic test was performed prior inoculation of the BTFs in order to evaluate the possibility of physical-chemical removal of the target pollutants by the packing materials. After that, three aliquots of $200 \mathrm{~mL}$ of fresh activated sludge were centrifuged for $10 \mathrm{~min}$ at 10,000 rpm. The supernatant was removed, and the biomass was resuspended in $100 \mathrm{~mL}$ of fresh MSM. The inoculum was then added to the holding tanks and recycled through the bed. The BTFs were initially operated at a gas retention time (GRT) of $2 \mathrm{~min}$, which was decreased to $1 \mathrm{~min}, 30 \mathrm{~s}, 15 \mathrm{~s}$ and $7.5 \mathrm{~s}$ in subsequent operating stages. Following the inoculation period, $150 \mathrm{~mL}$ of the cultivation medium were daily withdrawn for analysis and replaced with fresh MSM. This MSM renewal also maintained the $\mathrm{pH}$ above inhibitory levels. The mineral salt medium exchange rate was increased when decreasing the gas residence time, following an exchange ratio of $2.5 \mathrm{~L} \mathrm{MSM}\left(\mathrm{g} \mathrm{H}_{2} \mathrm{~S} \text { fed }\right)^{-1}$.

Inlet and outlet gas concentrations of $\mathrm{H}_{2} \mathrm{~S}$, methylmercaptan and toluene were daily analysed. Liquid samples from the recycling medium were periodically withdrawn in order to determine $\mathrm{pH}$ and sulfate concentration. The pressure drop across the packed beds was also periodically measured.

Phase II. The experimental setup consisted of two identical PVC biofilters (internal diameter $=0.1 \mathrm{~m}$, height $=1 \mathrm{~m}$, total working volume $=2.5 \mathrm{~L}$ ) packed with two different materials: Filtralite AIR 10-20 mm (BF-F) and Filtralite AIR AC (BF-FAC), and a twophase biotrickling filter packed with Filtralite AIR 10-20 mm (2PBTF-F) (Figure 1). The 
air stream entering the system was first pumped through an activated carbon filter, where any residual pollutant of atmospheric air was eliminated. The air was then humidified in a water column, entering afterwards a mixing chamber. In the mixing chamber, the clean and humidified air stream was mixed with a synthetic mixture of $\mathrm{H}_{2} \mathrm{~S}$, toluene and methyl mercaptan in $\mathrm{N}_{2}$ (purchased to Abelló Linde, Spain). The resulting polluted stream was initially divided into three identical streams of $1.25 \mathrm{~L} \mathrm{~min}^{-1}$ by means of rotameters. The individual streams were then fed at the bottom of each biofilter and the two-phase biotrickling filter. The clean air exiting the bioreactors was discharged outside the room using an extraction fan.

An abiotic test was initially conducted for 15 days at 2 min of GRT. The BFs and 2PBTF-F were then inoculated as above described and operated at GRTs of $2 \mathrm{~min}, 1 \mathrm{~min}$, $40 \mathrm{~s}$ and $20 \mathrm{~s}$ in subsequent operating stages. The biofilters were daily irrigated initially with $40 \mathrm{~mL}$ of MSM, increasing the flow rate to $80 \mathrm{~mL} \mathrm{~d}^{-1}, 120 \mathrm{~mL} \mathrm{~d}^{-1}$ and $192 \mathrm{~mL} \mathrm{~d}^{-1}$ when the BFs were operated at GRTs of $1 \mathrm{~min}, 40 \mathrm{~s}$ and $20 \mathrm{~s}$, respectively. A 0.5-L holding tank magnetically stirred was used as liquid reservoir for the 2PBTF-F, consisting of a mixture of $70 \% v / v$ of MSM and $30 \% v / v$ of silicone oil 20 cts (Sigma Aldrich, Madrid, Spain). The liquid was continuously recycled through the packed bed at a flowrate of 0.15 $\mathrm{L} \mathrm{min}^{-1}$ countercurrently with the polluted air stream (liquid trickling velocity of $2 \mathrm{~m} \mathrm{~h}^{-1}$ ). After inoculation, $150 \mathrm{~mL}$ of the cultivation medium (prior silicone oil separation) were daily withdrawn for analysis and replaced with fresh MSM in the 2PBTF-F at GRTs of 2 and $1 \mathrm{~min}$, respectively, while 225 and $360 \mathrm{~mL}$ were daily replaced at 40 and $20 \mathrm{~s}$, respectively.

Inlet and outlet gas concentrations of $\mathrm{H}_{2} \mathrm{~S}$, methylmercaptan and toluene were daily analysed. Liquid samples from the leachate of the BFs (when available) or from the recycling medium of the $\mathrm{BTF}$ were periodically withdrawn in order to determine $\mathrm{pH}$ and sulfate concentration. The pressure drop across the packed beds was also periodically measured.

Unless otherwise specified, the performance of the bioreactors is reported as the average removal efficiency under steady state for each operating condition (standard deviation $<5 \%$ ).

\subsection{Analytical Procedure}

Pollutants concentration was measured periodically both at the inlet and outlet of the bioreactors. Toluene was analyzed in a gas chromatograph equipped with a flame ionization detector and a HP-5-MS $(30 \mathrm{~m} \times 0.25 \mathrm{~mm} \times 0.25 \mu \mathrm{m})$ column. Solid-phase microextraction (SPME) was used as a pre-concentration technique during toluene analysis using $250 \mathrm{~mL}$ glass bulbs as sampling ports. $\mathrm{H}_{2} \mathrm{~S}$ and methylmercaptan were analyzed using portable detectors with specific sensors: Dräger X-am 5000 and Dräger X-am 7000, respectively.

Liquid samples were also withdrawn periodically from the holding tanks in order to determine $\mathrm{pH}$ and sulfate concentrations. The $\mathrm{pH}$ was daily measured using a $\mathrm{pHmeter}$ Eutech Cyberscan pH 510 (Eutech Instruments, Nijkerk, Netherlands). $\mathrm{SO}_{4}{ }^{2-}$ concentrations were measured by HPLC-IC. Finally, the pressure drop across the columns was also periodically determined using a U-meter filled with water as the manometric fluid.

\subsection{Microbial Community Analysis}

Samples from the inoculum and the final microbial communities present in the BTFs and BFs packed with Filtralite materials (at the end of the experimentation) were withdrawn for microbial analysis. The biomass was centrifuged at $13,000 \times g$ for $10 \mathrm{~min}$. The resulting pellet was used for DNA extraction using the MasterPure ${ }^{\mathrm{TM}}$ Complete DNA Purification Kit (Epicenter Biotechnologies, Madison, USA) according to the manufacturer's instructions. DNA was quantified with Qubit dsDNA broad-range (BR) assays in a QFX Fluorometer (DENOVIX, Wilmington, DE, USA) and subsequently purified. The extracted DNA was used for sequencing by Illumina Miseq. Sequencing was performed the Foundation for the Promotion of Health and Biomedical Research of the Valencia Region (FISABIO, 
Valencia Spain). Amplicon sequencing was developed targeting the 16S ribosomal DNA V3 and $\mathrm{V} 4$ regions using the bacterial/archaeal primers described by Klindworth [17]. Illumina adapter overhang nucleotide sequences were added to the gene-specific sequences. After 16S rRNA gene amplification, library construction was carried out using the Nextera XT DNA Sample Preparation Kit (Illumina, San Diego, CA, USA). Libraries were then normalized and pooled prior to sequencing. Samples containing indexed amplicons were loaded onto the MiSeq reagent cartridge for automated cluster generation sequencing using a $2 \times 300 \mathrm{pb}$ paired-end run (MiSeq Reagent kit v3 (MS-102-3001)) according to manufacturer's instructions (Illumina). Quality assessment and sequence joining was performed using prinseq-lite program [18] and bioinformatic analysis was done using an ad-hoc pipeline in RStatistics environment, making use of open-source libraries (gdata, vegan...). The sequence data was analyzed using qiime2 software tools. Taxonomic affiliations have been assigned using the Naive Bayesian classifier integrated in quiime2 plugins. The database used for this taxonomic assignation was the Silva138 [19].

\section{Results}

\subsection{Phase I: Biotrickling Filters Operation}

\subsubsection{System Performance: Odorants Abatement}

Under abiotic conditions, Filtralite AIR 10-20 supported a complete removal of $\mathrm{H}_{2} \mathrm{~S}$, while Filtralite AIR AC removed more than $90 \%$ of this contaminant. The performance of SAINT GOBAIN materials without inoculation outcompeted the removal efficiency of conventional plastic rings, which supported a $50 \%$ removal of $\mathrm{H}_{2} \mathrm{~S}$. Following inoculation, the BTF-FAC maintained a complete $\mathrm{H}_{2} \mathrm{~S}$ removal, while the BTF-F and the BTF-K rapidly achieved similar $\mathrm{H}_{2} \mathrm{~S}$ removals 2 and 4 days after inoculation, respectively. The three BTFs were capable of degrading inlet $\mathrm{H}_{2} \mathrm{~S}$ concentrations of $\sim 25 \mathrm{ppm}$ at GRTs of 2 and $1 \mathrm{~min}$ (Figure 2a). The GRT was reduced to 30 and $15 \mathrm{~s}$ by days 50 and 64, respectively, with no concomitant deterioration of the $\mathrm{H}_{2} \mathrm{~S}$ removal performance observed in any of the BTFs. Nevertheless, a further reduction of the GRT to $7.5 \mathrm{~s}$ resulted in an increase in the outlet $\mathrm{H}_{2} \mathrm{~S}$ concentration in BTF-F and BTF-K to $1.2 \mathrm{ppm}$ (corresponding to a removal efficiency of $95 \%$ ), while BTF-FAC was able to sustain a complete $\mathrm{H}_{2} \mathrm{~S}$ abatement.

Methylmercaptan was only analyzed from day 17 onwards of the experiment due to analytical issues at the initial stages of the project. No methylmercaptan was observed in the outlet gas stream of any BTF at GRTs of 2 and $1 \mathrm{~min}$. However, when the GRT was reduced to $30 \mathrm{~s}$, the outlet concentration of methylmercaptan increased to $2.5 \mathrm{mg} \mathrm{m}^{-3}$ in BTF-F and $2 \mathrm{mg} \mathrm{m}^{-3}$ in BTF-K and BTF-FAC, resulting in removal efficiencies of 28 and $42 \%$, respectively. In the last operating stages, at GRTs of 15 and $7.5 \mathrm{~s}$, no methylmercaptan removal was recorded in any of the BTFs (Figure 2b). 

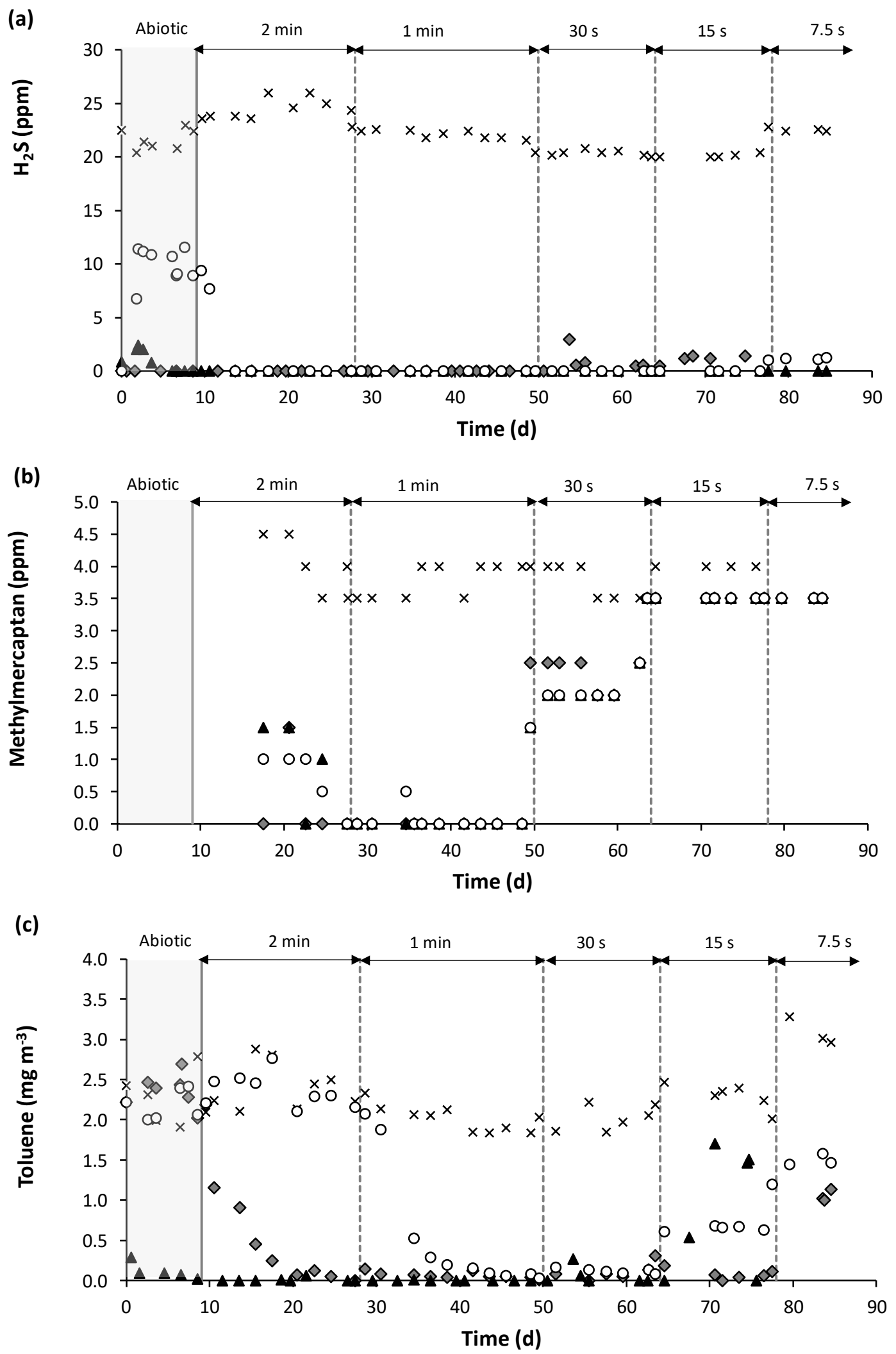

Figure 2. Time course of the inlet $(\times)$ and outlet concentration of $\mathrm{H}_{2} \mathrm{~S}(\mathbf{a})$, methylmercaptan $(\mathbf{b})$ and toluene (c) in BTF-F $(\checkmark)$, BTF-FAC $(\boldsymbol{\Lambda})$, BTF-K $(\bigcirc)$. Vertical dashed lines delimit different stages.

In the particular case of toluene, no removal was observed for the BTF packed with Kaldnes plastic rings during the first 27 days of operation, despite this biotrickling filter 
was inoculated with activated sludge by day 9 (Figure 2c). On the contrary, both BTFFAC and BTF-F reached toluene removal efficiencies of $>99 \%$ within 11 and 15 days after inoculation at a GRT of $2 \mathrm{~min}$. Surprisingly, a decrease in the residence time to $1 \mathrm{~min}$ promoted the abatement of toluene in BTF-K, achieving removals of $>99 \%$ from day 37 onwards at this GRT. The high toluene removal was also maintained in the three BTFs at a GRT of $30 \mathrm{~s}$. However, a further reduction in the GRT to $15 \mathrm{~s}$ resulted in a decrease in the toluene removal performance of BTF-K, increasing the outlet toluene concentration up to $0.65 \mathrm{mg} \mathrm{m}^{-3}$ (which corresponded to a removal efficiency of $72 \%$ ). On the contrary, both BTF-F and BTF-FAC were able to maintain toluene removal efficiencies $>99 \%$, which highlights the good performance of SAINT GOBAIN packing materials during biotrickling filtration of VOCs. Finally, the reduction in the GRT to $7.5 \mathrm{~s}$ resulted in a deterioration in the toluene removal performance regardless of the BTF, with average toluene outlet concentrations of $1.5 \mathrm{mg} \mathrm{m}^{-3}$ (corresponding to removal efficiencies of $50 \%$ ) for BTF-K and BTF-FAC and $1 \mathrm{mg} \mathrm{m}^{-3}$ for BTF-F (corresponding to a removal efficiency of $67 \%$ ).

\subsubsection{Analysis of the Liquid Phase and Pressure Drop across the Bed}

The $\mathrm{pH}$ measurements started during the biotic phase of the process in the recycling liquid. The $\mathrm{pH}$ remained roughly stable in the BTF-FAC, with initial values of $6.4 \pm 0.0$ and a final value of $6.1 \pm 0.0$ in the last operating stage at a GRT of $7.5 \mathrm{~s}$ (Figure 3a). On the contrary, a significant $\mathrm{pH}$ drop was observed in the BTF packed with plastic rings, reaching minimum values of 2.8 after 15 days of operation. After this initial drop, the $\mathrm{pH}$ in BTF-K stabilized at $\sim 2-2.2$, slightly decreasing in the last operating stage to average values of $1.7 \pm 0.3$. In the case of BTF-F, after the initial $\mathrm{pH}$ stabilization by day 20 , a sharp drop was recorded along with the increase in $\mathrm{H}_{2} \mathrm{~S}$ load, reaching values of $\sim 3.3$ by day 36. From this day onwards, a steady decrease was observed in the $\mathrm{pH}$ of the recycling liquid, reaching values of $2.0 \pm 0.1$ when operating at a GRT of $7.5 \mathrm{~s}$. This decrease in the $\mathrm{pH}$ of the recirculation liquid solution was associated to the aerobic oxidation of $\mathrm{H}_{2} \mathrm{~S}$ to sulphate and the concomitant accumulation of this byproduct. Finally, a stable sulphate concentration of $\sim 1650 \mathrm{mg} \mathrm{SO}_{4}{ }^{-2} \mathrm{~L}^{-1}$ was recorded in the trickling liquid of the BTF-F for the first 22 days of operation. Then, sulphate concentration fluctuated from a minimum value of $1186 \mathrm{mg} \mathrm{SO}_{4}{ }^{-2} \mathrm{~L}^{-1}$ on day 51 to a maximum of $1811 \mathrm{mg} \mathrm{SO}_{4}{ }^{-2} \mathrm{~L}^{-1}$ on day 36. Sulphate concentration increased from 796 to $1605 \mathrm{mg} \mathrm{SO}_{4}{ }^{-2} \mathrm{~L}^{-1}$ and from 264 to $753 \mathrm{mg} \mathrm{SO}_{4}{ }^{-2} \mathrm{~L}^{-1}$ by days 9 to 16 of operation in the BTF-FAC and the BTF-K, respectively. Then, the concentrations of $\mathrm{SO}_{4}{ }^{-2}$ gradually increased reaching a maximum of $1897 \mathrm{mg} \mathrm{SO}_{4}{ }^{-2} \mathrm{~L}^{-1}$ in BTF-FAC by day 71 of operation and $1672 \mathrm{mg} \mathrm{SO}_{4}{ }^{-2} \mathrm{~L}^{-1}$ by day 64 in BTF-K. These concentrations were far below inhibitory concentrations of sulphate for $\mathrm{H}_{2} \mathrm{~S}$ degrading bacteria.

The pressure drop remained stable in the three systems at values of $\sim 9 \mathrm{mmH}_{2} \mathrm{O}$ $\mathrm{m}_{\text {bed }}{ }^{-1}$ in BTF-FAC and BTF-K, and was slightly lower in BTF-F $\left(\sim 6 \mathrm{mmH}_{2} \mathrm{O} \mathrm{m}_{\text {bed }}{ }^{-1}\right)$ when working at a GRT of $2 \mathrm{~min}$. Concomitant increases in the pressure drop were recorded when decreasing the GRT, reaching values of $15 \mathrm{mmH}_{2} \mathrm{O}_{\text {bed }}{ }^{-1}$ at $1 \mathrm{~min}, 19 \mathrm{mmH}_{2} \mathrm{O}$ $\mathrm{m}_{\text {bed }}{ }^{-1}$ at $30 \mathrm{~s}, 35 \mathrm{mmH}_{2} \mathrm{O} \mathrm{m}$ bed $^{-1}$ at $15 \mathrm{~s}$ and $\sim 55 \mathrm{mmH}_{2} \mathrm{O}_{\text {bed }}{ }^{-1}$ at $7.5 \mathrm{~s}$ regardless of the BTF (Figure 3b). 
(a)

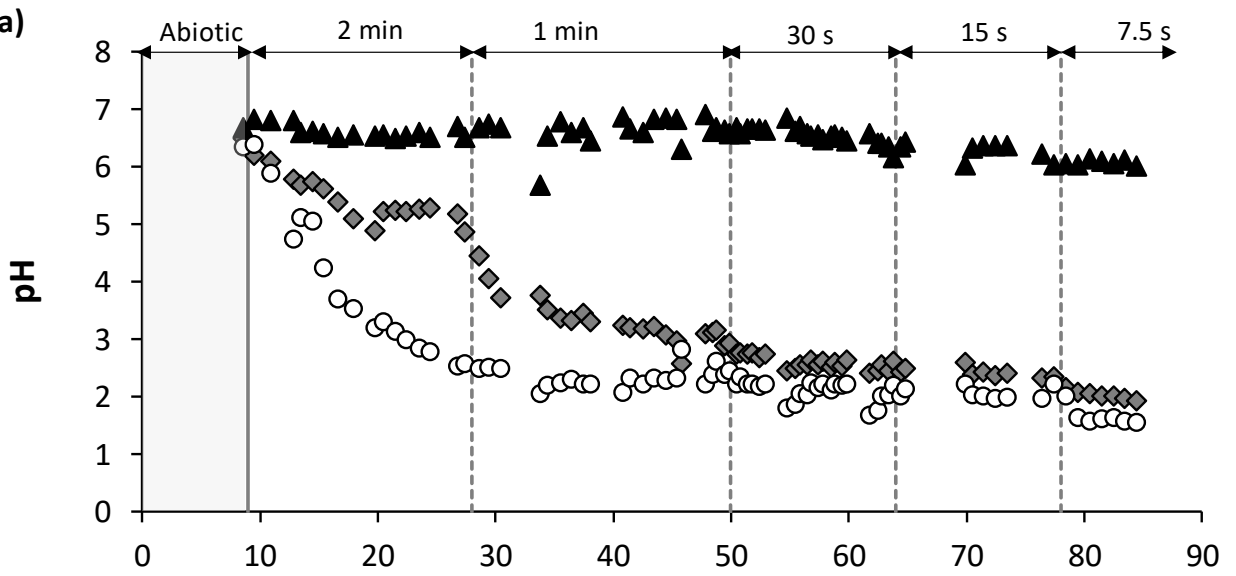

(b)

Time (d)

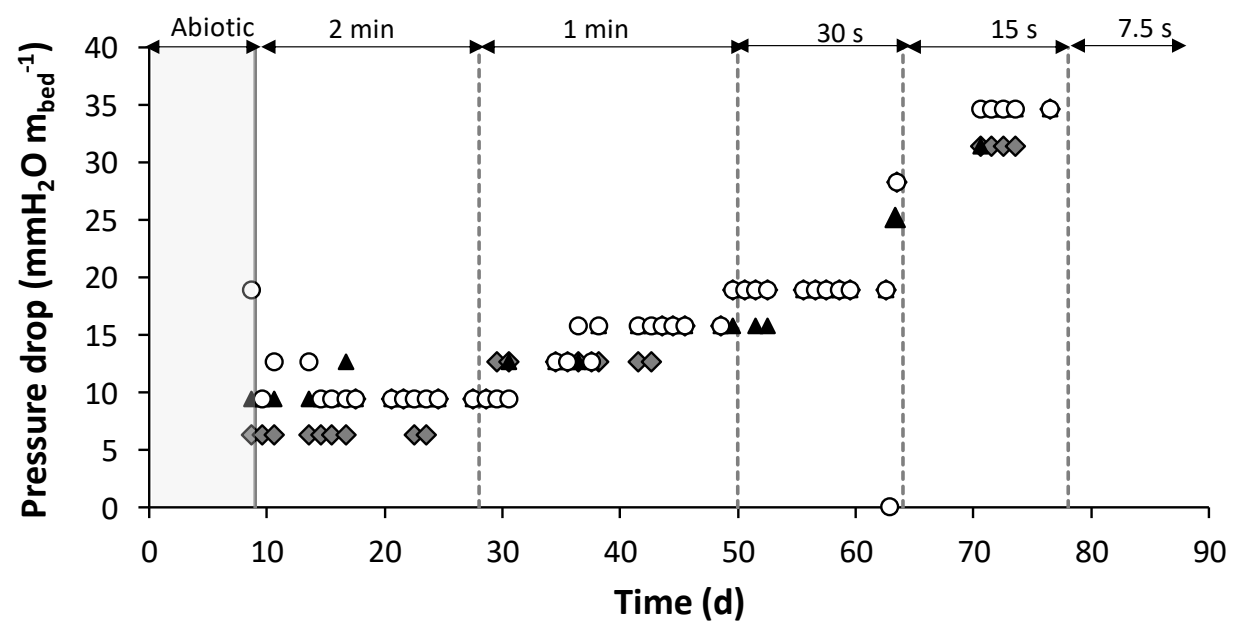

Figure 3. Time course of (a) pH and (b) pressure drop in the BTF-F $(\bullet)$, the BTF-FAC $(\boldsymbol{\Delta})$ and the BTF-K $(\bigcirc)$. Vertical dashed lines delimit different stages.

\subsection{Phase II: Biofilters and Two-Phase Biotrickling Filter Operation}

3.2.1. System Performance: Odorants Abatement

Under abiotic conditions, 2PBTF-F and BF-FAC supported a complete removal of $\mathrm{H}_{2} \mathrm{~S}$ by day 0 , while the $\mathrm{H}_{2} \mathrm{~S}$ removal efficiency recorded in the BF-F gradually dropped from $90 \%$ by day 1 to $\sim 55 \%$ by day 15 of abiotic operation (Figure 4 a). The three bioreactors were capable of biologically degrading inlet $\mathrm{H}_{2} \mathrm{~S}$ concentrations of $19.9 \pm 2.2 \mathrm{ppm}$, completely removing the $\mathrm{H}_{2} \mathrm{~S}$ immediately after inoculation of the systems. The decrease in GRT from 2 min to 1 min and $40 \mathrm{~s}$ did not affect the $\mathrm{H}_{2} \mathrm{~S}$ removal performance, no $\mathrm{H}_{2} \mathrm{~S}$ being detected in the treated air exiting the bioreactors throughout these operational stages (regardless of the packing material or presence of trickling aqueous-silicone oil solution). Similarly, BF-FAC and 2PBTF-F supported a complete $\mathrm{H}_{2} \mathrm{~S}$ removal at $20 \mathrm{~s}$ of GRT, whereas the steady $\mathrm{H}_{2} \mathrm{~S}$ removal efficiency of BF-F slightly decreased during this last experimental period to $97.5 \pm 0.3 \%$. 


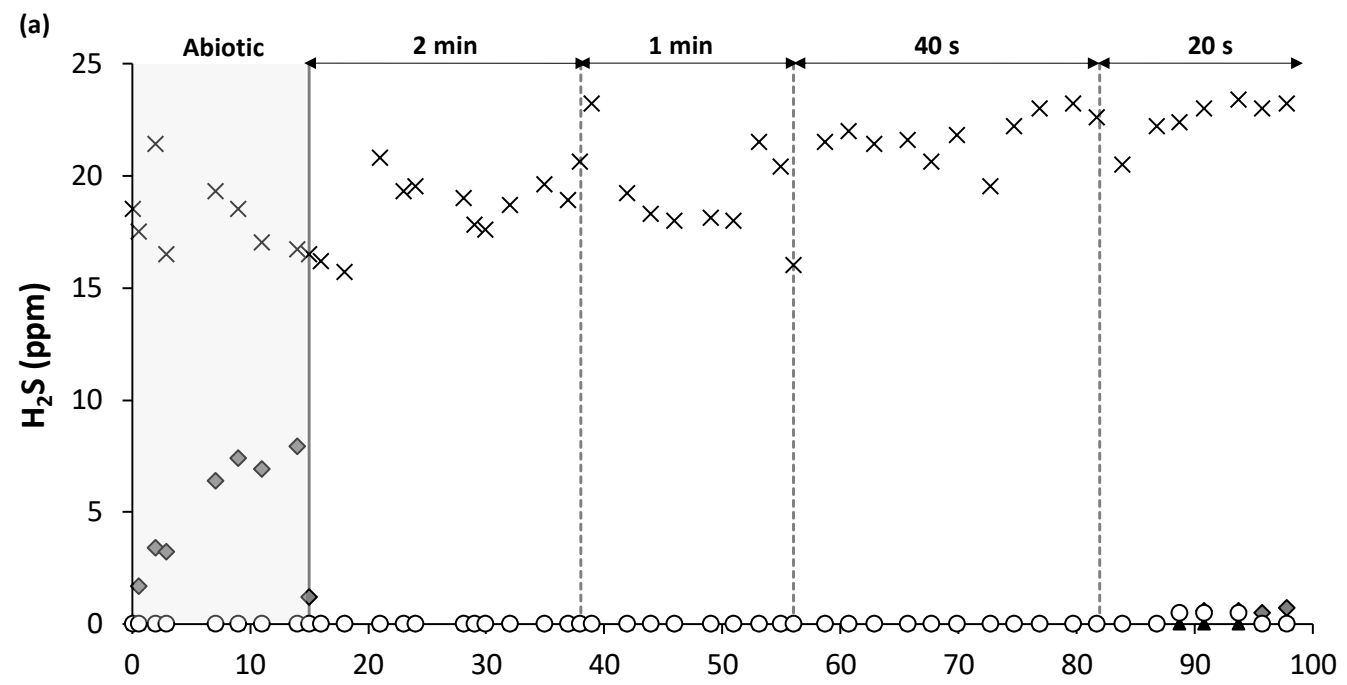

(b)

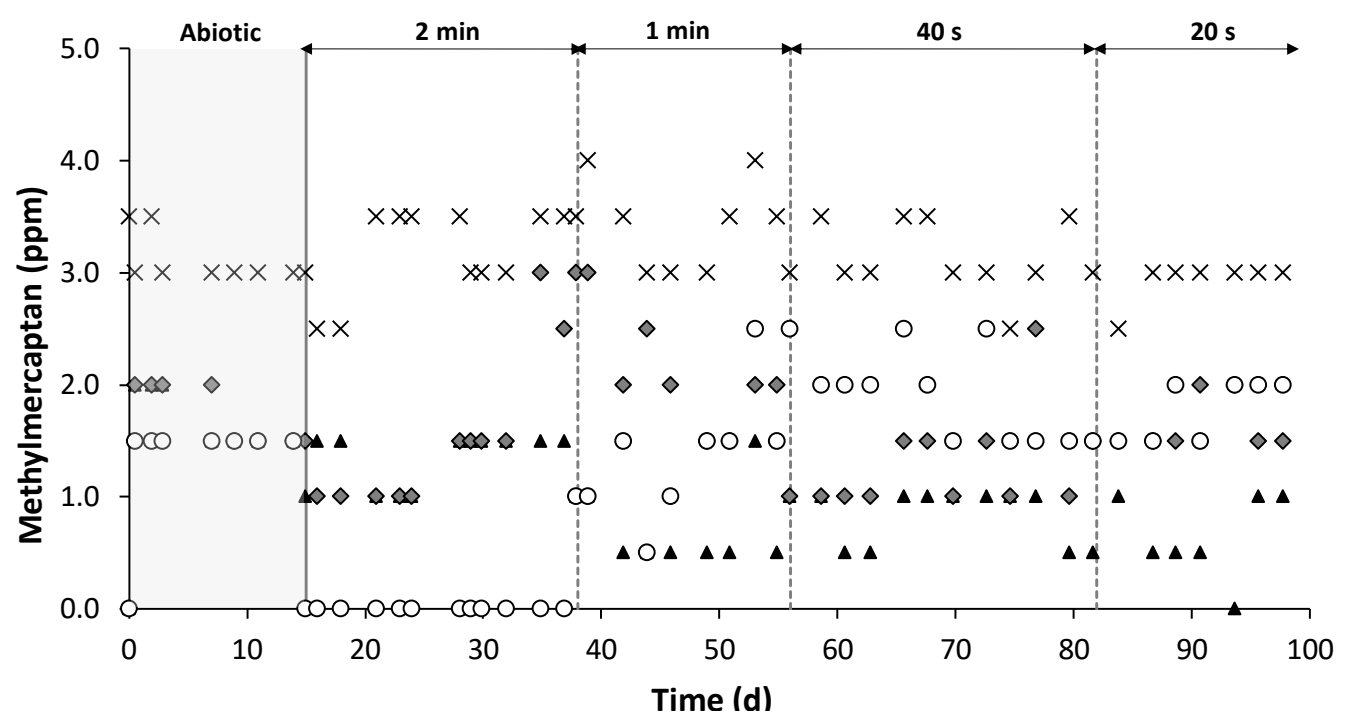

(c)

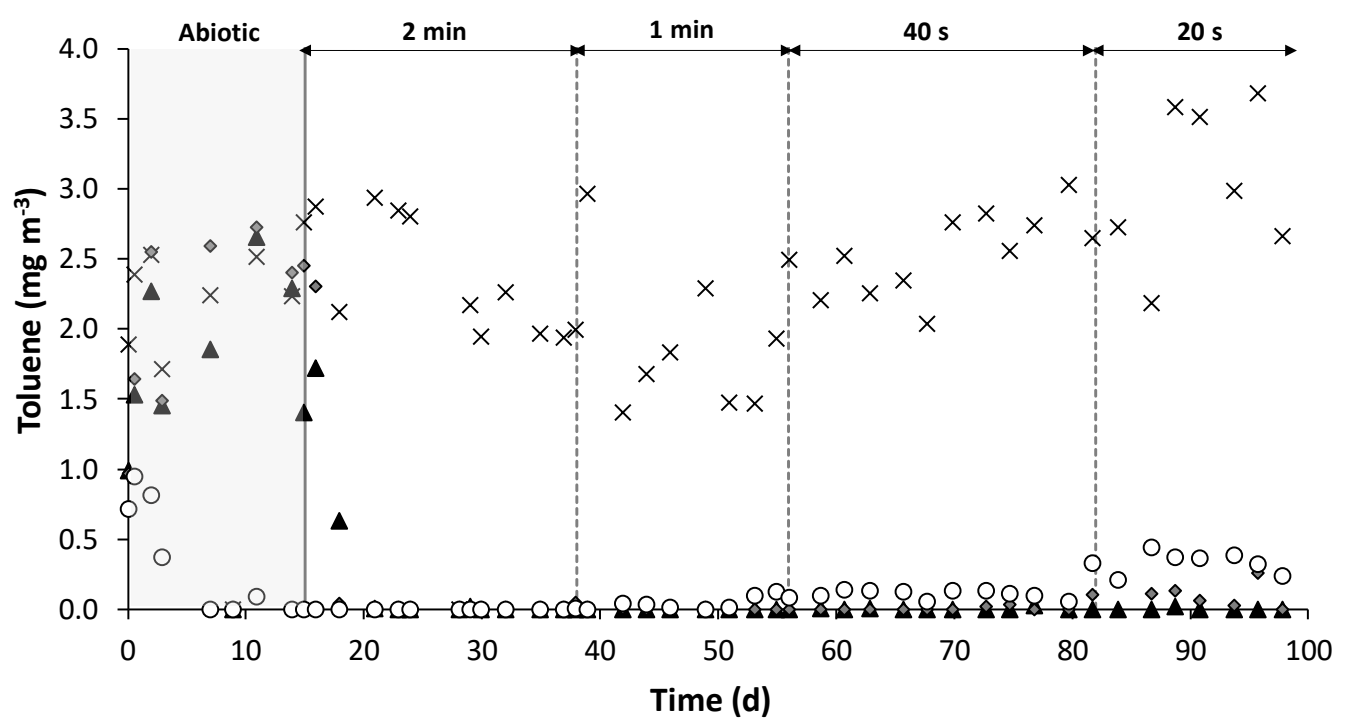

Figure 4. Time course of the inlet $(\times)$ and outlet concentration of $\mathrm{H}_{2} \mathrm{~S}(\mathbf{a})$, methylmercaptan $(\mathbf{b})$ and toluene (c) in BF-F ( $)$, BF-FAC $(\boldsymbol{\Delta})$ and 2PBTF-F $(\bigcirc)$. Vertical dashed lines delimit different stages. 
Methylmercaptan concentration was reduced from 3 to $1.5 \mathrm{ppmv}$ regardless of the packing material and bioreactor configuration from day 8 of the abiotic period (Figure $4 b$ ). After inoculation, MM removal remained similar in both biofilters, while the two-phase BTF packed with Filtralite AIR 10-20 mm achieved a complete removal of MM at a GRT of 2 min. Surprisingly, a decrease in the GRT from 2 to 1 min resulted in a higher MM abatement in BF-FAC (up to $~ 80 \%$ ), which supported a removal efficiency $>78 \%$ at 40 and $20 \mathrm{~s}$ of GRT. On the contrary, when the GRT was reduced to $1 \mathrm{~min}$, a concomitant decrease in the MM abatement performance to $~ 50 \%$ was observed in the BF-F and the 2PBTF-F. A further decrease in the GRT to $40 \mathrm{~s}$ resulted in average removal efficiencies of $63 \pm 7 \%$ and $42 \pm 9 \%$ in BF-F and 2PBTF-F, respectively. Finally, both bioreactors supported average MM removals of $\sim 45 \%$ at 20 s of GRT.

In the particular case of toluene, a negligible removal was observed in the biofilters packed with Filtralite AIR 10-20 mm or Filtralite AIR AC during the 15 days of abiotic operation (Figure 4c). On the contrary, the 2PBTF-F reached toluene removal efficiencies $>99 \%$ by day 7 under abiotic conditions. After inoculation, toluene was completely removed regardless of the bioreactor, although 6 days were necessary for BF-F to achieve a complete removal. A decrease in the GRT from $2 \mathrm{~min}$ to $1 \mathrm{~min}$ and $40 \mathrm{~s}$ slightly reduced toluene removal in the 2 PBTF-F to $~ 98$ and $96 \%$, respectively, while no effect was observed in the biofilters performance. Finally, the biofilter packed with Filtralite AIR AC (BF-FAC) was able to completely remove the toluene from the polluted air stream, while the toluene removal efficiency of BF-F and 2PBTF-F dropped to $96 \pm 3 \%$ and $89 \pm 4 \%$, respectively, at the lowest GRT of $20 \mathrm{~s}$.

\subsubsection{Analysis of the Liquid Phase and Pressure Drop across the Bed}

The $\mathrm{pH}$ measurements started during the abiotic phase of the process in the recycling liquid of the 2PBTF, gradually decreasing from 7.36 to 4.73 by the end of the operation at a GRT of 1 min and stabilizing at $\sim 3.0$ during the last two operational stages (Figure 5a). This acidification of the 2PBTF-F recycling liquid was attributed to the oxidation of $\mathrm{H}_{2} \mathrm{~S}$ to sulphate. In the particular case of biofilters, the $\mathrm{pH}$ of the leachate was monitored from day 31 onwards (when leachate appeared as a result of packing media saturation with water), remaining stable in BF-F at a value of $2.2 \pm 0.5$ and slightly dropping from 6.6 to 4.2 by day 55 in BF-FAC, stabilizing afterwards at $2.5 \pm 0.3$.

The pressure drop remained stable at values of $\sim 5 \mathrm{mmH}_{2} \mathrm{O} \mathrm{m}_{\text {bed }}{ }^{-1}$ during process operation at $2 \mathrm{~min}$ of GRT in the three systems, and increased up to $\sim 8.5 \mathrm{mmH}_{2} \mathrm{O} \mathrm{m}_{\text {bed }}{ }^{-1}$ at a GRT of $1 \mathrm{~min}$ (Figure 5b). After decreasing the GRT to 40 and $20 \mathrm{~s}$, the 2PBTF-F and the BF-FAC exhibited a reduced pressure drop of $\sim 12.6$ and $13.4 \mathrm{mmH}_{2} \mathrm{O} \mathrm{m}_{\text {bed }}{ }^{-1}$, respectively. However, in the BF packed with Filtralite AIR 10-20 mm, an increase in the pressure drop up to 15.1 and $34.6 \mathrm{mmH}_{2} \mathrm{O} \mathrm{m}_{\text {bed }}{ }^{-1}$ was recorded at 40 and $20 \mathrm{~s}$ of GRT, respectively. 
(a)
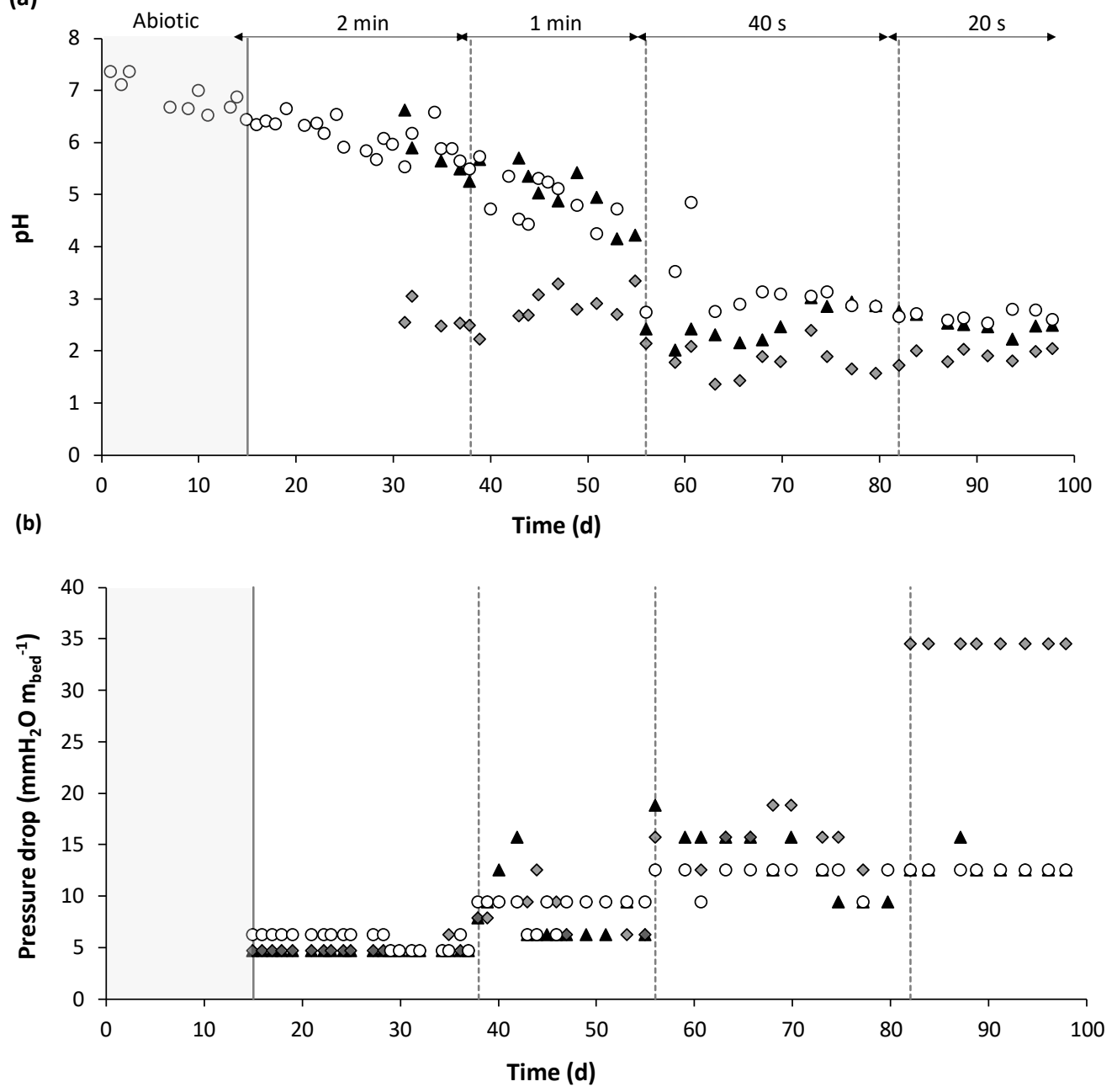

Figure 5. Time course of $(\mathbf{a}) \mathrm{pH}$ and $(\mathbf{b})$ pressure drop in the BF-F $(\downarrow)$, the BF-FAC $(\mathbf{\Lambda})$ and the 2PBTF-F $(\mathrm{O})$. Vertical dashed lines delimit different stages.

\subsection{Microbial Communities}

The Read numbers after quality filtering and chimera filtering were 120,146 (inoculum), 134,416 (BTF-FAC), 124,396 (BTF-F), 132,622 (BF-FAC) and 30,030 (BF-F). The rarefaction curves of operational taxonomic units (OTUs) from the samples analyzed reached the plateau, demonstrating that the sequencing depth was sufficient to cover the diversity of the microbial communities in the bioreactors (Supplementary Figure S1).

Samples BF-FAC and BF-F presented 465 and 161 OTUs, respectively. The number of OTUs in the inoculum, BTF-F and BTF-FAC were 312, 78 and 382. respectively. Diversity estimator Shannon index showed the highest values for the inoculum (4.09), BF-F (4.24), and BF-FAC (3.29), while BTF-FAC and BTF-F showed lower values (2.7 and 1.78, respectively).

The inoculum, based on fresh activated sludge from Valladolid wastewater treatment plant, was dominated by microbial members of the phylum Proteobacteria (55\%). Actinobacteria (10\%), Firmicutes (22\%), Bacteroidota (4\%) and Cyanobacteria $(4 \%)$ were the next most abundant phyla. The BTF-FAC was clearly dominated by members of the phylum Proteobacteria (91\%), followed by less represented phyla such as Actinobacteria (3\%), Verrucomicrobia, Chloroflexi, Bacteroidota (1\% each). Proteobacteria also dominated the BTF-F but with less representation (66\%). Actinobacteria was the second most abundant phyla (26\%), followed by Acidobacteriota (5\%). Proteobacteria was the most abundant phylum in the BF-FAC (72\%), followed by Planctomycetota (15\%), Actinobacteria and Chloroflexi ( $4 \%$ each one), Verrucomicrobia $(2 \%)$ and other less represented phyla. Al- 
though Proteobacteria was also the most abundant (32\%) phylum in the BF-F, this biofilter presented a wider range of bacterial phyla including Bacteroidota (17\%), Firmicutes (9\%), Actinobacteria and Verrucomicrobia ( $8 \%$ each one), Patescibacteria (5\%), Acidobacteria and Sinergistaceae (3\% each) and other less represented phyla. (Supplementary Figure S2).

\section{Discussion}

The results here obtained confirmed clay-based packing materials from SAINT GOBAIN company as a promising platform for the optimization of the performance of biofilters and biotrickling filters devoted to the removal of odorants from different characteristics (VOC and VIC).

In this context, Filtralite materials showed better adsorption capacities when the bioreactors were operated under abiotic conditions, also supporting a more rapid startup after inoculation. The presence of water in the materials under abiotic conditions enhanced their ability to remove $\mathrm{H}_{2} \mathrm{~S}$, as confirmed by the superior performance of the BTFs compared to BFs. A similar $\mathrm{H}_{2} \mathrm{~S}$ and $\mathrm{MM}$ abatement was supported by the three BTFs, achieving almost complete removals at $7.5 \mathrm{~s}$ and $1 \mathrm{~min}$, respectively. On the contrary, Filtralite materials showed a superior toluene removal efficiency, exhibiting values $>99 \%$ at $15 \mathrm{~s}$ of GRT, while toluene removal in the BTF packed Kaldnes plastic rings remained at $\sim 70 \%$. At this point it should be highlighted that the Henry's law constants of $\mathrm{H}_{2} \mathrm{~S}$, toluene and methyl mercaptan are $1 \times 10^{-3}, 1.5 \times 10^{-3}$ and $3.5 \times 10^{-3} \mathrm{~mol}\left(\mathrm{~m}^{3} \mathrm{~Pa}\right)^{-1}$. This rules out a potential mass transfer limitation causing the deterioration of methylmercaptan removal based only on the mass transfer gradient. Gas-liquid mass transfer in biotrickling filters depends, not only on the gas-liquid concentration gradient, but also on the mass transfer coefficient $\left(\mathrm{K}_{\mathrm{L}} \mathrm{a}\right)$, which itself is a function of the pollutant. Indeed, $\mathrm{K}_{\mathrm{L}} \mathrm{a}$ is proportional to the (molar volume of the pollutant) ^ 0.4 , where the molar volume for $\mathrm{H}_{2} \mathrm{~S}$, toluene and methylmercaptan are 33, 106 and $55 \mathrm{~mL} \mathrm{~mol}^{-1}$, respectively. The results suggest that Filtralite Air AC was able to support better methylmercaptan removal efficiencies due to the higher metabolic activity of the microbial community as a result of the higher $\mathrm{pH}$ values provided by the packing material compared to plastic rings. In this context, the sharp initial decrease in the $\mathrm{pH}$ of the trickling liquid recorded in the BTF-K was likely detrimental for the microbial activity and might explain the lower MM and toluene removal performance observed in the biotrickling filter packed with plastic rings.

In addition to the superior abatement performances obtained at 7-15 s (typical gas residence times for the operation of BTFs at a commercial scale), SAINT GOBAIN materials provided pressure drops as low as those of conventional plastic rings, which foresees a good performance of these materials in terms of energy demand during odour abatement. In this context, $10 \mathrm{~cm}$ of water column is often considered as the maximum tolerable pressure drop in biofiltration to avoid severe operating costs [20,21]. In our particular study, this value was not exceeded at any of the gas flowrates tested, even at $7.5 \mathrm{~s}$ of gas residence time $\left(<3.5 \mathrm{cmH}_{2} \mathrm{O}\right)$, which demonstrates the technical viability of the tested materials.

In biofilters, lower air velocities, and thus higher residence times are typically provided to accomplish an effective air pollutant treatment. For instance, for $\mathrm{H}_{2} \mathrm{~S}$ and VOCs removal, typical values ranging from 40 to $60 \mathrm{~s}$ are usually suggested [22]. However, negligible $\mathrm{H}_{2} \mathrm{~S}$ concentrations were recorded at the outlet of the biofilters and the two-phase biotrickling filter packed with SAINT GOBAIN materials even at the lowest GRT of 20 s. On the contrary, the two-phase BTF did not show any improvement regarding methylmercaptan and toluene removal. Previous studies have demonstrated a superior removal performance of hydrophobic VOCs such as hexane in two-phase partitioning bioreactors, due to an enhanced mass transfer of the pollutant from the gas phase to the microorganisms [4]. Similarly, Darraq et al. (2010) reported gas-silicone oil partition coefficients for sulfur compounds such as DMS and DMDS up to 30 times lower than those values for gaswater systems [23]. Therefore, it could be hypothesized that the limited methylmercaptan abatement here obtained was not associated to mass transfer limitations but rather to a low 
microbial activity. Overall, Filtralite AIR AC outcompeted Filtralite Air 10-20 mm for the abatement of the three model odorants, while supporting the lowest pressure drop (despite its lower particle size) and the highest buffer capacity at 40 and $20 \mathrm{~s}$. Previous studies on odour treatment using compost-based biofilters have achieved an efficient abatement of odorants ( $>95 \%$ for $\mathrm{H}_{2} \mathrm{~S}$, butanone and toluene) at GRTs ranging from 30 up to $94 \mathrm{~s}$, although at the expense of an important pressure drop across the filter bed (from 6 up to $33 \mathrm{~cm}$ of water column) due to the compaction of the organic packing material [20].

Toluene degraders were mainly distributed among the Proteobacteria and Actinobacteria phyla in the BFs and BTFs, although Actinobacteria were less represented in the reactors packed with Filtrate Air 10-20 mm. Members of Pseudomonadales, Burkholderiales, Xanthomonadales (within Betaproteobacteria) and Rhizobiales (within Alfaproteobacteria) are known to biodegrade toluene [24], and these microorganisms were present in all bioreactors. Among Actinobacteria, Mycobacterium, a well-known toluene degrader [25], was a key player in toluene degradation in BFs and BTFs.

It is important to note that Filtrate Air AC packing material favored the development of Proteobacteria as the clear dominant phyla in BFs and BTFs, while the dominance of this group in BFs and BTFs packed with Filtrate Air 10-20 was less pronounced. In fact, aerobic oxidation of methyl mercaptan is performed by members of Proteobacteria such as Thiobacillus, Hyphomicrobium, Pseudomonas, Methylophaga and Klebsiella [26]. Microorganisms of the genus Thiobacillus, Halothiobacillus and Acidithiobacillus within the Proteobacteria phylum were detected and were likely involved in methyl mercaptan degradation in the BF-FAC, BTF-F and BTF-FAC. Thiobacillus thioparus is able to oxidize methyl mercaptan producing elemental sulfur and sulfate [27] and different Thiobacillus species have been previously found in BFs and BTFs treating methyl mercaptan and other sulfur odorants [15,28,29]. Some species of Thiobacillus have been reclassified in the genera Halothiobacillus and Acidithiobacillus [30] and their ability to degrade methyl mercaptan cannot be ruled out. On the contrary, BF-F did not show aerobic methyl mercaptan oxidizers. Instead, Archaea, that were exclusively present in this bioreactor, likely degraded this compound, since the ability of Archaea such as Methanomethylovorans hollandica, Methanolobus and Methanomethylovorans to anaerobically degrade methyl mercaptan has been demonstrated [31-33]. These results suggest that the higher performance in terms of methyl mercaptan removal in BF-FAC as compared to BF-F, could be mediated by the development of aerobic methyl mercaptan oxidizers, that were not found in the biofilter packed with Filtrate Air 10-20. Similarly, BFFAC showed a higher population of Thiobacillus, Acidithiobacillus and Halothiobacillus (56\%) than BF-F (25\%), which also could have influenced the better performance of BTF-FAC at GRT of $30 \mathrm{~s}$; although none of the microbial communities were able to support methyl mercaptan removal at lower GRTs. Overall, these results demonstrate the relevance of the packing material in shaping the desired microbial communities.

\section{Conclusions}

SAINT GOBAIN clay-based packing materials exhibited a superior performance compared to conventional plastic-based carriers for the abatement of model odorous compounds $\left(\mathrm{H}_{2} \mathrm{~S}\right.$, toluene and methylmercaptan) when implemented both in biofilter and biotrickling filter configurations. Their superior performance at gas residence times as low as $7.5 \mathrm{~s}$, together with their comparable pressure drops to those of plastic rings, open up new opportunities for boosting the cost-effectiveness of biotechnologies for odour abatement. Among the materials tested in biofilters, Filtralite Air AC supported an almost complete $\mathrm{H}_{2} \mathrm{~S}$ and toluene abatement and $\sim 80 \%$ methylmercaptan removals at a gas residence time of $20 \mathrm{~s}$. Hence, SAINT GOBAIN materials have the potential to become the core of a new generation of advanced biofilters based on the combination of high buffer capacity, high water retention, good gas-liquid mass transfer, low pressure drops and high structural resistance. 
Supplementary Materials: The following are available online at https:/ / www.mdpi.com/2076-3 417/11/7/2966/s1, Figure S1: Rarefaction curves of OTUs from the samples analyzed, Figure S2: Krona Plots showing taxonomic classification of the microorganisms in the samples analyzed

Author Contributions: Conceptualization: R.M., C.D.J., G.N., K.R. and R.L.; methodology: M.C. and E.R.; writing—original draft preparation: R.L., E.R., R.M.; supervision: C.D.J., G.N. and K.R.; project administration: R.M.; funding acquisition: K.R. All authors have read and agreed to the published version of the manuscript.

Funding: This research was funded by SAINT GOBAIN, LECA International.

Institutional Review Board Statement: Not applicable.

Informed Consent Statement: Not applicable.

Data Availability Statement: Not applicable.

Acknowledgments: The Regional Government of Castilla y León and the EU-FEDER program [grant number CLU 2017-09] are also gratefully acknowledged.

Conflicts of Interest: The authors declare no conflict of interest.

\section{References}

1. Hayes, J.E.; Stevenson, R.J.; Stuetz, R.M. Survey of the effect of odour impact on communities. J. Environ. Manag. 2017, 204, 349-354. [CrossRef] [PubMed]

2. Alfonsín, C.; Lebrero, R.; Estrada, J.M.; Muñoz, R.; Kraakman, N.J.R.; Feijoo, G.; Moreira, M.A.T. Selection of odour removal technologies in wastewater treatment plants: A guideline based on Life Cycle Assessment. J. Environ. Manag. 2015, 149, 77-84. [CrossRef]

3. Estrada, J.M.; Lebrero, R.; Quijano, G.; Kraakman, B.; Muñoz, R. Odour abatement technologies in WWTPs: Energy and economic efficiency. In Sewage Treatment Plants: Economic Evaluation of Innovative Technologies for Energy Efficiency; Tsagarakis, K., Stamatelatou, K., Eds.; IWA Publishing: London, UK, 2015; pp. 163-187.

4. Lebrero, R.; Rodríguez, E.; Pérez, R.; García-Encina, P.A.; Muñoz, R. Abatement of odorant compounds in one- and two-phase biotrickling filters under steady and transient conditions. Appl. Microbiol. Biotechnol. 2013, 97, 4627-4638. [CrossRef]

5. Delhoménie, M.C.; Bibeau, L.; Heitz, M. A study of the impact of particle size and adsorption phenomena in a compost-based biological filter. Chem. Eng. Sci. 2002, 57, 4999-5010. [CrossRef]

6. Lebrero, R.; Muñoz, R.; Villaverde, S.; Hung, Y.-T. Air Biofiltration Applied to Odor Treatment; World Scientific Publlishing: Beijing, China, 2012; ISBN 9789814327701.

7. Estrada, J.M.; Lebrero, R.; Quijano, G.; Kraakman, N.J.R.; Muñoz, R. Strategies for Odour Control. In Odour Impact Assessment Handbook; Belgiorno, V., Naddeo, V., Zarra, T., Eds.; John Wiley \& Sons: New York, NY, USA, 2012; ISBN 9781119969280.

8. Rene, E.R.; Murthy, D.V.S.; Swaminathan, T. Effect of Flow Rate, Concentration and Transient-State Operations on the Performance of a Biofilter Treating Xylene Vapors. Water Air Soil Pollut. 2010, 211, 79-93. [CrossRef]

9. Iranpour, R.; Cox, H.H.J.; Deshusses, M.A.; Schroeder, E.D. Literature review of air pollution control biofilters and biotrickling filters for odor and volatile organic compound removal. Environ. Prog. 2005, 24, 254-267. [CrossRef]

10. Janni, K.A.; Maier, W.J.; Kuehn, T.H.; Yang, C.-H.; Bridges, B.B.; Vesley, D.; Nellis, M.A. Evaluation of Biofiltration of Air-An Innovative Air Pollution Control Technology. In Proceedings of the ASHRAE Winter Meeting CD, Technical and Symposium Papers, Atlanta, GA, USA, 1 January 2001; pp. 263-279.

11. Das, J.; Rene, E.R.; Dupont, C.; Dufourny, A.; Blin, J.; van Hullebusch, E.D. Performance of a compost and biochar packed biofilter for gas-phase hydrogen sulfide removal. Bioresour. Technol. 2019, 273, 581-591. [CrossRef]

12. Cárdenas-González, B.; Ergas, S.J.; Switzenbaum, M.S.; Phillibert, N. Evaluation of full-scale biofilter media performance. Environ. Prog. 1999, 18, 205-211. [CrossRef]

13. Devinny, J.; Deshusses, M.; Webster, T. Biofiltration for Air Pollution Control; Taylor \& Francis Group: Boca Raton, FL, USA, 2017; ISBN 9781315138275.

14. Lebrero, R.; Rangel, M.G.L.; Muñoz, R. Characterization and biofiltration of a real odorous emission from wastewater treatment plant sludge. J. Environ. Manag. 2013, 116, 50-57. [CrossRef]

15. Lebrero, R.; Gondim, A.C.; Pérez, R.; García-Encina, P.A.; Muñoz, R. Comparative assessment of a biofilter, a biotrickling filter and a hollow fiber membrane bioreactor for odor treatment in wastewater treatment plants. Water Res. 2014, 49, 339-350. [CrossRef]

16. Kennes, C.; Veiga, M.C. Inert filter media for the biofiltration of waste gases-Characteristics and biomass control. Rev. Environ. Sci. Biotechnol. 2002, 1, 201-214. [CrossRef]

17. Klindworth, A.; Pruesse, E.; Schweer, T.; Peplies, J.; Quast, C.; Horn, M.; Glöckner, F.O. Evaluation of general 16S ribosomal RNA gene PCR primers for classical and next-generation sequencing-based diversity studies. Nucleic Acids Res. 2013, 41, e1. [CrossRef] [PubMed] 
18. Schmieder, R.; Edwards, R. Quality control and preprocessing of metagenomic datasets. Bioinformatics 2011, 27, 863-864. [CrossRef] [PubMed]

19. Quast, C.; Pruesse, E.; Yilmaz, P.; Gerken, J.; Schweer, T.; Yarza, P.; Peplies, J.; Glöckner, F.O. The SILVA ribosomal RNA gene database project: Improved data processing and web-based tools. Nucleic Acids Res. 2013, 41, 590-596. [CrossRef]

20. Lebrero, R.; Rodríguez, E.; García-Encina, P.A.; Muñoz, R. A comparative assessment of biofiltration and activated sludge diffusion for odour abatement. J. Hazard. Mater. 2011, 190, 622-630. [CrossRef]

21. Delhoménie, M.-C.; Heitz, M. Biofiltration of Air: A Review. Crit. Rev. Biotechnol. 2005, 25, 53-72. [CrossRef] [PubMed]

22. Federation, W.E. Odor Control. In Operation of Municipal Wastewater Treatment Plants; McGraw-Hill Education: New York, NY, USA, 2008; ISBN 9780071543675.

23. Dumont, E.; Darracq, G.; Couvert, A.; Couriol, C.; Amrane, A.; Thomas, D.; Andrès, Y.; Le Cloirec, P. Volumetric mass transfer coefficients characterising VOC absorption in water/silicone oil mixtures. Chem. Eng. J. 2013, 221, 308-314. [CrossRef]

24. Timmis, K.N.; McGenity, T.J.; van der Meer, J.R.; de Lorenzo, V. (Eds.) Handbook of Hydrocarbon and Lipid Microbiology; Springer: Berlin/Heidelberg, Germany, 2010; ISBN 978-3-540-77584-3.

25. Zhang, L.; Zhang, C.; Cheng, Z.; Yao, Y.; Chen, J. Biodegradation of benzene, toluene, ethylbenzene, and o-xylene by the bacterium Mycobacterium cosmeticum byf-4. Chemosphere 2013, 90, 1340-1347. [CrossRef]

26. Torres, F.A.T. Addendum to the Toxicological Profile for Methyl Mercaptan; Agency for Toxic Substances and Disease Registry: Atlanta, Georgia, 2014.

27. Badr, K.; Bahmani, M.; Jahanmiri, A.; Mowla, D. Biological removal of methanethiol from gas and water streams by using Thiobacillus thioparus: Investigation of biodegradability and optimization of sulphur production. Environ. Technol. 2014, 35, 1729-1735. [CrossRef]

28. Maestre, J.P.; Rovira, R.; Álvarez-Hornos, F.J.; Fortuny, M.; Lafuente, J.; Gamisans, X.; Gabriel, D. Bacterial community analysis of a gas-phase biotrickling filter for biogas mimics desulfurization through the rRNA approach. Chemosphere 2010, 80, 872-880. [CrossRef]

29. Tu, X.; Xu, M.; Li, J.; Li, E.; Feng, R.; Zhao, G.; Huang, S.; Guo, J. Enhancement of using combined packing materials on the removal of mixed sulfur compounds in a biotrickling filter and analysis of microbial communities. BMC Biotechnol. 2019, 19, 52. [CrossRef] [PubMed]

30. Kelly, D.P.; Wood, A.P. Reclassification of some species of Thiobacillus to the newly designated genera Acidithiobacillus gen. nov., Halothiobacillus gen. nov. and Thermithiobacillus gen. nov. Int. J. Syst. Evol. Microbiol. 2000, 50 Pt 2, 511-516. [CrossRef]

31. Lomans, B.P.; Maas, R.; Luderer, R.; Op Den Camp, H.J.M.; Pol, A.; Van Der Drift, C.; Vogels, G.D. Isolation and characterization of Methanomethylovorans hollandica gen. nov., sp. nov., isolated from freshwater sediment, a methylotrophic methanogen able to grow on dimethyl sulfide and methanethiol. Appl. Environ. Microbiol. 1999, 65, 3641-3650. [CrossRef] [PubMed]

32. van Leerdam, R.C.; de Bok, F.A.M.; Bonilla-Salinas, M.; van Doesburg, W.; Lomans, B.P.; Lens, P.N.L.; Stams, A.J.M.; Janssen, A.J.H. Methanethiol degradation in anaerobic bioreactors at elevated $\mathrm{pH}(8)$ : Reactor performance and microbial community analysis. Bioresour. Technol. 2008, 99, 8967-8973. [CrossRef] [PubMed]

33. de Bok, F.A.M.; van Leerdam, R.C.; Lomans, B.P.; Smidt, H.; Lens, P.N.L.; Janssen, A.J.H.; Stams, A.J.M. Degradation of methanethiol by methylotrophic methanogenic archaea in a lab-scale upflow anaerobic sludge blanket reactor. Appl. Environ. Microbiol. 2006, 72, 7540-7547. [CrossRef] [PubMed] 